\title{
Evaluation of Corneal Biomechanical Properties Following Penetrating Keratoplasty Using the Ocular Response Analyzer
}

\author{
Joo Young Shin ${ }^{1,2}$, Jin Seok Choi ${ }^{1,2}$, Joo Youn $\mathrm{Oh}^{1,2}$, Mee Kum Kim ${ }^{1,2}$, Jin Hak Lee ${ }^{1,2}$, Won Ryang Wee \\ ${ }^{1}$ Department of Ophthalmology, Seoul National University Hospital, Seoul, Korea \\ ${ }^{2}$ Seoul Artificial Eye Center, Seoul National University Hospital Clinical Research Institute, Seoul, Korea
}

\begin{abstract}
Purpose: To evaluate corneal biomechanical properties in eyes that had previously undergone penetrating keratoplasty (PK) using the ocular response analyzer (ORA).

Methods: We recruited 26 patients who had received unilateral $\mathrm{PK}$. Corneal hysteresis $(\mathrm{CH})$, corneal resistance factor (CRF), Goldmann-correlated intraocular pressure (IOPg), and cornea-compensated intraocular pressure (IOPcC) were measured with the ORA and were compared to the measurements from the contralateral eyes that did not undergo PK.

Results: The $\mathrm{CH}$ was $8.95 \pm 2.59 \mathrm{mmHg}$ in eyes that underwent $\mathrm{PK}$ and $9.78 \pm 1.45 \mathrm{mmHg}$ in the contralateral eyes that did not undergo PK $(p=0.077)$. The CRF was $10.26 \pm 2.64 \mathrm{mmHg}$ in post-PK eyes and $9.75 \pm 1.45 \mathrm{mmHg}$ in the contralateral eyes $(p=0.509)$, and the $\mathrm{CH}-\mathrm{CRF}$ was significantly smaller in post-PK eyes $(-1.31 \pm 2.32 \mathrm{mmHg}$ in post-PK eyes vs. $0.03 \pm 0.88 \mathrm{mmHg}$ in fellow eyes, $p=0.016$ ). The IOPg and IOPcc were significantly higher in the PK group than they were in the control group. The IOPcc's were $20.81 \pm 7.81 \mathrm{mmHg}$ and $16.27 \pm 2.49 \mathrm{mmHg}$ in post-PK and control eyes, respectively ( $p=0.011$ ); and the IOPg's were $19.22 \pm 7.34 \mathrm{mmHg}$ and $15.07 \pm 3.03$ $\mathrm{mmHg}$ in post-PK and control eyes, respectively $(p=0.019)$. The IOPcc-g's were $1.59 \pm 2.81 \mathrm{mmHg}$ and $1.21 \pm 1.30$ $\mathrm{mmHg}$ in post-PK and control eyes, respectively $(p=0.412)$, and the central corneal thickness (CCT)'s were $489.11 \pm 90.60 \mu \mathrm{m}$ and $556.24 \pm 42.84 \mu \mathrm{m}$ in post-PK and control eyes, respectively $(p=0.068)$.

Conclusions: Following PK, CH tended to decrease while CRF tended to increase, significantly decreasing $\mathrm{CH}-\mathrm{CRF}$. A significantly higher intraocular pressure and a thinner CCT following PK may have contributed to the observed changes in these corneal biomechanical parameters.
\end{abstract}

Key Words: Cornea, Intraocular pressure, Penetrating keratoplasty

The ocular response analyzer (ORA, Reichert Ophthalmic Instruments, Depew, NY, USA) can measure corneal biomechanical properties such as corneal hysteresis $(\mathrm{CH})$ and corneal resistance factor (CRF) [1]. In addition, noncontact intraocular pressures such as the Goldmann-correlated intraocular pressure (IOPg) and corneal-compensated intraocular pressure (IOPcc) can be measured by the ORA. The ORA detects the pressure at which the cornea is flattened as it is indented with an air puff and the pressure at which it is flattened as it returns to its original shape. Corneal hysteresis is

Received: June 1, 2009 Accepted: May 11, 2010

Reprint requests to Won Ryang Wee. Department of Ophthalmology, Seoul National University Hospital, \#28 Yeongeon-dong, Jongno-gu, Seoul 110-744, Korea. Tel: 82-2-2072-2435, Fax: 82-2-741-3187, E-mail: wrwee@snu.ac.kr defined as the difference between these two pressures and is thought to represent the viscosity of the cornea. The mean of these two pressures is the IOPg. The IOPcc is a pressure measurement that utilizes the $\mathrm{CH}$ measurement to determine an intraocular pressure (IOP) value that is less affected by corneal properties such as central corneal thickness (CCT). Moreover, many previous studies have reported that the IOPcc is unrelated to CCT [1-5]. CRF is an empirically determined parameter that is thought to represent the overall resistance of the cornea [6]. ORA measurement of these parameters has previously been reported to demonstrate good reproducibility and clinical reliability [7].

Although the significance of these ORA parameters is not fully understood, several studies have reported changes in these parameters in various diseases, as well as following certain procedures. $\mathrm{CH}$ has been shown to be significantly lower in eyes with keratoconus [1,8,9], Fuchs' dystrophy 
$[1,10]$, high myopia [11], glaucoma [1,5], and inpost-laser in situ keratomileusis (LASIK) eyes [2,12]. Following clear corneal incision cataract surgery, $\mathrm{CH}$ and $\mathrm{CRF}$ were found to be decreased at one day postoperatively; this change was maintained for one week, after which the pressure increased back to baseline by one month postoperatively [13].

Penetrating keratoplasty (PK) is frequently performed for various corneal pathologies. However, there have previously been no studies using the ORA to measure the biomechanical properties of post-PK eyes. As such, we measured the corneal biomechanical properties of patients that had previously undergone unilateral PK using the ORA and compared the measurements with those of the normal contralateral eyes.

\section{Materials and Methods}

This study was approved by the Institutional Review Board of the Clinical Research Institute of Seoul National University Hospital.

Twenty-six eyes that had previously undergone PK for unilateral corneal disease at Seoul National University Hospital were included in this study. Slit lamp biomicroscopic examination was performed at the time of recruitment in order to exclude any patients with noticeable pathology in the contralateral eye and to identify evidence of rejection or recurrence in the post-PK eye. Further studies were performed on an as-needed basis. Patients with no evidence of rejection, infection, or recurrence of disease in the post-PK eye and with no evidence of disease in the contralateral eye were included.

The ORA (Reichert Ophthalmic Instruments) was used to measure CH, CRF, IOPg, and IOPcc in both the post-PK and contralateral normal eyes. One examiner performed all of the measurements with three consecutive readings in each eye, including only good-quality measurements with two distinct peaks. The mean of the three measurements was used for statistical analysis. CCT was measured with the ORA-attached handheld ultrasonic pachymeter.

All statistical analyses were performed with SPSS ver. 15.0 (SPSS Inc., Chicago, IL, USA). The Wilcoxon signed rank test was used to analyze the difference in each ORA parameter between the post-PK and contralateral eyes. Correlation between parameters was evaluated with Spearman's rho correlation. A $p$-value less than 0.05 was considered statisti-
Table 1. Patient demographics

\begin{tabular}{lc}
\hline \multicolumn{1}{c}{ Parameter } & Mean \pm SD (range) \\
\hline Age (yr) & $53.73 \pm 14.43(16-78)$ \\
\hline Gender (male:female) & $8: 18$ \\
\hline Laterality (right:left) & $9: 17$ \\
\hline Time since operation (mon) & $19.00 \pm 21.60(1-108)$ \\
\hline
\end{tabular}

Table 2. Underlying diseases requiring penetrating keratoplasty

\begin{tabular}{lc}
\hline \multicolumn{1}{c}{ Underlying disease } & Number of patients \\
\hline Bullous keratopathy & 8 \\
Herpes keratitis & 6 \\
Trauma & 6 \\
Iridocorneal endothelial syndrome & 3 \\
Infectious keratitis & 1 \\
Neurotrophic ulcer & 1 \\
Unknown & 1 \\
\hline
\end{tabular}

cally significant.

\section{Results}

The mean patient age was $53.73 \pm 14.43$ years, and eight of the patients were male. The mean duration since undergoing PK was 19 months. Demographic data of the patients is summarized in Table 1. The causative diseases requiring PK are shown in Table 2.

All eyes underwent PK using the conventional 16 interrupted suture technique performed by two surgeons (KMK and OJY).

The ORA parameters in the post-PK eyes and the contralateral normal eyes are shown in Table 3. $\mathrm{CH}$ was decreased in the post-PK eyes, but this difference was not statistically significant $(8.95 \pm 2.59 \mathrm{mmHg}$ in the post-PK eyes vs. $9.78 \pm 1.45 \mathrm{mmHg}$ in the contralateral normal eyes; $p=0.077)$. CRF was higher in the post-PK eyes than in the fellow eyes, but without statistical significance $(10.26 \pm 2.64 \mathrm{mmHg}$ in the post-PK eyes vs. $9.75 \pm 1.45 \mathrm{mmHg}$ in the fellow eyes; $p=0.509)$. The IOPcc and IOPg were significantly higher in the post-PK group than in the control group (IOPcc, $20.81 \pm 7.81 \mathrm{mmHg}$ in the post-PK eyes and $16.27 \pm 2.49$ $\mathrm{mmHg}$ in the contralateral eyes, $p=0.011 ; \mathrm{IOPg}, 19.22 \pm 7.34$ $\mathrm{mmHg}$ in the post-PK eyes and $15.07 \pm 3.03 \mathrm{mmHg}$ in the fel-

Table 3. The ocular response analyzer values for post-penetrating keratoplasty eyes and normal contralateral eyes

\begin{tabular}{lccccccc}
\hline & $\begin{array}{c}\mathrm{CH} \\
(\mathrm{mmHg})\end{array}$ & $\begin{array}{c}\mathrm{CRF} \\
(\mathrm{mmHg})\end{array}$ & $\begin{array}{c}\text { CH-CRF } \\
(\mathrm{mmHg})\end{array}$ & $\begin{array}{c}\mathrm{CCT} \\
(\mu \mathrm{m})\end{array}$ & $\begin{array}{c}\text { IOPcc } \\
(\mathrm{mmHg})\end{array}$ & $\begin{array}{c}\text { IOPg } \\
(\mathrm{mmHg})\end{array}$ & $\begin{array}{c}\text { IOPcc-g } \\
(\mathrm{mmHg})\end{array}$ \\
\hline Post-PK & $8.95 \pm 2.59$ & $10.26 \pm 2.64$ & $-1.31 \pm 2.32$ & $489.11 \pm 90.60$ & $20.81 \pm 7.81$ & $19.22 \pm 7.34$ & $1.59 \pm 2.81$ \\
Normal & $9.78 \pm 1.04$ & $9.75 \pm 1.45$ & $0.03 \pm 0.88$ & $556.24 \pm 42.84$ & $16.27 \pm 2.49$ & $15.07 \pm 3.03$ & $1.21 \pm 1.30$ \\
$p$-value & 0.077 & 0.509 & 0.016 & 0.068 & 0.011 & 0.019 & 0.412 \\
\hline
\end{tabular}

Values are presented as Mean \pm SD.

$\mathrm{CH}=$ corneal hysteresis; $\mathrm{CRF}=$ corneal resistance factor; $\mathrm{CH}-\mathrm{CRF}=\mathrm{CH}$ and $\mathrm{CRF}$; $\mathrm{CCT}=$ central corneal thickness; $\mathrm{IOPcc}=$ cornea-compensated intraocular pressure; IOPg = Goldmann-correlated intraocular pressure; IOPcc-g $=\mathrm{IOPcc}$ and IOPg; PK=penetrating keratoplasty. 

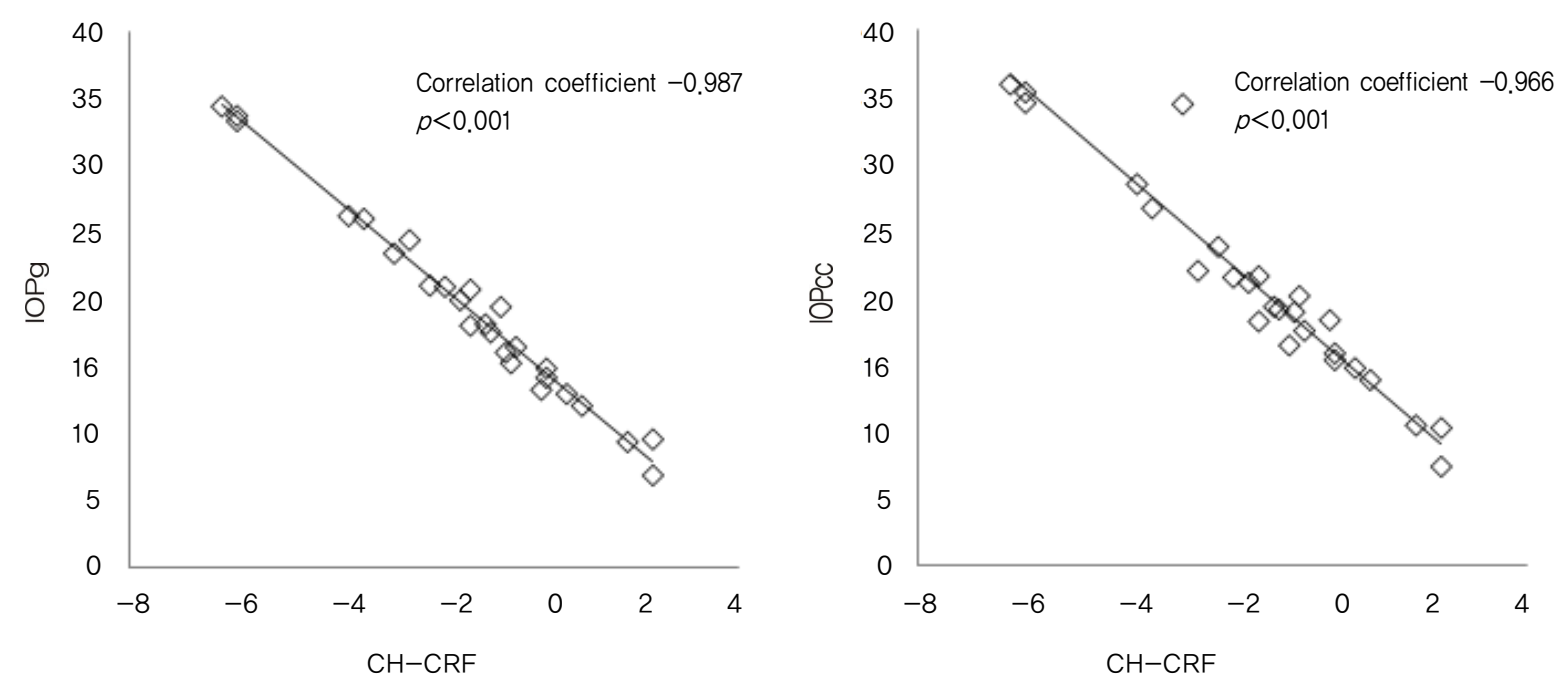

Fig. 1. Correlations of corneal hysteresis $(\mathrm{CH})$ and corneal resistance factor $(\mathrm{CRF})$ with cornea-compensated intraocular pressure (IOPcc) and Goldmann-correlated intraocular pressure (IOPg).
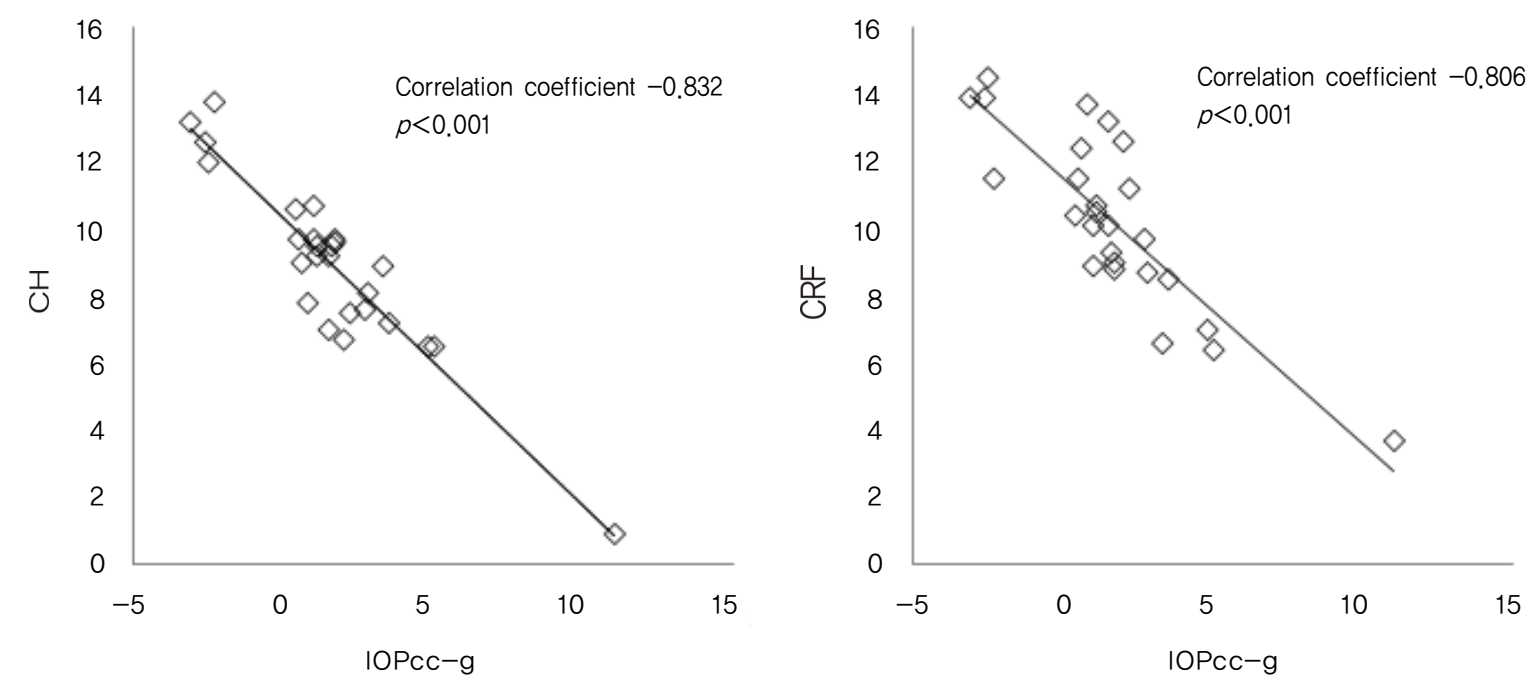

Fig. 2. Correlations of cornea-compensated intraocular pressure and Goldmann-correlated intraocular pressure (IOPcc-g) with corneal hysteresis $(\mathrm{CH})$ and corneal resistance factor $(\mathrm{CRF})$.

low eyes, $p=0.019)$. In addition, the CCTs were $489.11 \pm$ $90.60 \mu \mathrm{m}$ and $556.24 \pm 42.84 \mu \mathrm{m}$ in the post-PK and fellow eyes, respectively ( $p=0.068)$.

In addition to the four basic parameters measured by the ORA, the difference between $\mathrm{CH}$ and $\mathrm{CRF}$ and the difference between IOPcc and IOPg (IOPcc-g) were calculated and analyzed between the groups. CH-CRF was significantly smaller in post-PK eyes than in contralateral eyes $(-1.31 \pm 2.32$ $\mathrm{mmHg}$ in post-PK eyes vs. $0.03 \pm 0.88 \mathrm{mmHg}$ in fellow eyes, $p=0.016)$. CH-CRF was negatively correlated with IOPcc (correlation coefficient, -0.966; $p<0.001$ ) and IOPg (correlation coefficient, -0.987; $p<0.001$ ) (Fig. 1). IOPcc-g was not significantly different between post-PK eyes and contralateral eyes $(1.59 \pm 2.81 \mathrm{mmHg}$ in post-PK eyes vs. $1.21 \pm 1.30 \mathrm{mmHg}$ in fellow eyes; $p=0.412$ ). IOPcc-g demonstrated a negative correlation with both $\mathrm{CH}$ (correlation coefficient, -0.832 ; $p<0.001$ ) and CRF (correlation coefficient, -0.806; $p<0.001$ ) (Fig. 2).

\section{Discussion}

$\mathrm{CH}$ is known to represent the viscosity of the cornea, reflecting the collagen structure and hydration state of the cornea. $\mathrm{CH}$ is believed to have little association with CCT or IOP, although the degree of association varies among reports [14]. It has been reported that $\mathrm{CH}$ is decreased in keratoconus, Fuchs' dystrophy, high myopia, and glaucoma, as well as in post-LASIK corneas and in the immediate postoperative period following cataract surgery using a clear corneal incision. In this study, we found that $\mathrm{CH}$ tended to decrease in post-PK 
eyes.

CRF is thought to represent the elasticity of the cornea, with stronger correlations with IOP and CCT compared to those of $\mathrm{CH}$. CRF has also been reported to be decreased in keratoconus, Fuchs' dystrophy, and in post-LASIK eyes. Our study demonstrated that there was no significant difference in CRF between post-PK eyes and normal fellow eyes; only a slight increase was observed in post-PK eyes.

Regarding the difference between $\mathrm{CH}$ and $\mathrm{CRF}$, previous reports have demonstrated that $\mathrm{CH}-\mathrm{CRF}$ is negative in both normal and glaucoma subjects and positive in keratoconus and post-LASIK subjects [14]. Also, CH-CRF has been reported to be increased in eyes with high myopia and elevated IOPg and IOPcc [11]. As for the mechanism of this change in glaucomatous eyes, previous investigators have theorized that "corneal remodeling" results in decreased $\mathrm{CH}$ as a response to glaucomatous damage and that a high CRF represents a stiffened cornea resulting from high IOP [14]. We found that $\mathrm{CH}-\mathrm{CRF}$ was significantly lower in post-PK eyes compared to those of fellow eyes. This might be attributed to the fact that the IOPg and IOPcc were both significantly higher in post-PK eyes in this study. It remains uncertain whether the duration of increased IOP was sufficient in these patients to induce "corneal remodeling;" however, significant decreases in $\mathrm{CH}$ and $\mathrm{CH}-\mathrm{CRF}$ in the post-PK eyes might be associated with higher IOPs. The strong negative correlations of CH-CRF with IOPcc and IOPg further support this hypothesis.

Additionally, although both IOPcc and IOPg were higher in post-PK eyes, IOPcc-g was not significantly different in the post-PK eyes. Given that IOPcc-g is thought to reflect the degree of cornea-induced IOP measurement error [4]; these findings suggest that cornea-induced IOP measurement error was not significantly higher in post-PK eyes than it was in normal eyes.

In contrast to the irregular applanation signal previously reported for a transplanted cornea [1], the applanation curves acquired in all the patients in our study were similar to the curves acquired from normal subjects, with no noticeable irregularities.

This study has several limitations in terms of the small number of eyes studied and the heterogeneities of the underlying conditions requiring PK. In addition, this study is a cross-sectional study. A prospective, controlled study with a large number of patients is needed to further characterize corneal biomechanical changes following PK procedures.

In conclusion, our study revealed that $\mathrm{CH}$ tended to decrease and $\mathrm{CRF}$ tended to increase following PK, resulting in a significant decrease in $\mathrm{CH}-\mathrm{CRF}$. These changes may have been influenced by an increase in IOP and a decrease in CCT in the post-PK eyes.

\section{Conflict of Interest}

No potential conflict of interest relevant to this article was reported.

\section{References}

1. Luce DA. Determining in vivo biomechanical properties of the cornea with an ocular response analyzer. $J$ Cataract Refract Surg 2005;31:156-62.

2. Ortiz D, Pinero D, Shabayek MH, et al. Corneal biomechanical properties in normal, post-laser in situ keratomileusis, and keratoconic eyes. J Cataract Refract Surg 2007;33:1371-5.

3. Pepose JS, Feigenbaum SK, Qazi MA, et al. Changes in corneal biomechanics and intraocular pressure following LASIK using static, dynamic, and noncontact tonometry. Am J Ophthalmol 2007;143:39-47.

4. Medeiros FA, Weinreb RN. Evaluation of the influence of corneal biomechanical properties on intraocular pressure measurements using the ocular response analyzer. $J$ Glaucoma 2006; 15:364-70.

5. Lam A, Chen D, Chiu R, Chui WS. Comparison of IOP measurements between ORA and GAT in normal Chinese. Optom Vis Sci 2007;84:909-14.

6. Sullivan-Mee M, Billingsley SC, Patel AD, et al. Ocular Response Analyzer in subjects with and without glaucoma. Optom Vis Sci 2008;85:463-70.

7. Moreno-Montanes J, Maldonado MJ, Garcia N, et al. Reproducibility and clinical relevance of the ocular response analyzer in nonoperated eyes: corneal biomechanical and tonometric implications. Invest Ophthalmol Vis Sci 2008;49:968-74.

8. Kirwan C, O'Malley D, O'Keefe M. Corneal hysteresis and corneal resistance factor in keratoectasia: findings using the Reichert ocular response analyzer. Ophthalmologica 2008; 222:334-7.

9. Shah S, Laiquzzaman M, Bhojwani R, et al. Assessment of the biomechanical properties of the cornea with the ocular response analyzer in normal and keratoconic eyes. Invest Ophthalmol Vis Sci 2007;48:3026-31.

10. del Buey MA, Cristobal JA, Ascaso FJ, et al. Biomechanical properties of the cornea in Fuchs' corneal dystrophy. Invest Ophthalmol Vis Sci 2009;50:3199-202.

11. Shen M, Fan F, Xue A, et al. Biomechanical properties of the cornea in high myopia. Vision Res 2008;48:2167-71.

12. Gatinel D, Chaabouni S, Adam PA, et al. Corneal hysteresis, resistance factor, topography, and pachymetry after corneal lamellar flap. J Refract Surg 2007;23:76-84.

13. Kucumen RB, Yenerel NM, Gorgun E, et al. Corneal biomechanical properties and intraocular pressure changes after phacoemulsification and intraocular lens implantation. J Cataract Refract Surg 2008;34:2096-8.

14. Touboul D, Roberts C, Kerautret J, et al. Correlations between corneal hysteresis, intraocular pressure, and corneal central pachymetry. J Cataract Refract Surg 2008;34:616-22. 